https://doi.org/10.35520/metamorfoses.2018.v15n2a19900

\title{
DUAS VEZES HELENA: APONTAMENTOS SOBRE SUA OBRA E SUA VERSÃO EM MANGÁ
}

\author{
TWICE HELENA: NOTES ON ITS ORIGINAL TEXT AND ITS \\ MANGA VERSION
}

Pedro Panhoca da Silva

\begin{abstract}
RESUMO
Busca-se apontar elementos que auxiliaram a adaptação da obra Helena (1876), de Machado de Assis e publicada no folhetim O Globo (1876), para seu formato em mangá produzido pela editora NewPOP (2014) usando como base a teoria da adaptação de Hutcheon (2013), análises de Braga Jr (2011) e Lipszyc (1972), bem como outros textos releventes, incluindo impressões próprias. Foi possível perceber que muitos componentes visuais e verbais da nova obra podem ser encontrados também no original, assim como outros recursos presentes em outros folhetins da época.
\end{abstract}

Palavras-chave: Helena; Machado de Assis; Mangá.

1 Graduado em Letras pela Universidade Estadual Paulista Júlio de Mesquita Filho/Assis (2007), Especialista em Ensino de Português, Literatura e Redação pelo Centro Educacional Claretiano (CEUCLAR) (2009), Mestre pela UNESP/Assis e Doutorado em curso no Programa de Pós-Graduação em Letras da Universidade Presbiteriana Mackenzie, com bolsa da referida instituição. Atualmente é professor do Centro Universitário Herminio Ometto de Araras (UNIARARAS). Tem experiência na área de Letras, com ênfase em Literatura Infanto-juvenil, atuando principalmente nos seguintes temas: produção textual, leitura, livros-jogos. É também membro dos grupos de pesquisa "Poéticas da negatividade" - coordenado pelo Prof. Dr. Fabiano Rodrigo da Silva Santos -, e "Literatura no contexto pós-moderno" - coordenado pela Prof. Dra. Helena Bonito Couto Pereira, além de ser editorcolaborador/colunista da revista LEGENDARY ART MAGAZINE, colaborador do fanzine/revista ALARUMS \& EXCURSIONS e editor o banco de dados gamebooks.org.

Metamorfoses, Rio de Janeiro, vol. 15, número 2, p. 72-84, 2019. 


\begin{abstract}
It is intended to point out elements that helped adapt the text Helena (1876), by Machado de Assis and published in O Globo (1876) leaflet, for its format in manga produced by the publisher NewPOP (2014), based on the theory of adaptation of Hutcheon (2013), analyzes of Braga Jr (2011) and Lipszyc (1972), as well as other relevant texts, including own impressions. It was possible to perceive that many visual and verbal components of the new text can be found also in the original, as well as other resources present in other leaflets of that time.
\end{abstract}

Keywords: Helena; Machado de Assis; Manga

\title{
1. Introdução
}

Os quadrinhos, antes um subproduto nocivo por parte da sociedade norte-americana dos anos 50, adquiriram o status de cult, impulsionados pelo título de nona arte $^{2}$, conquistado há alguns anos. Os quadrinhos brasileiros, porém, parecem ser taxados como mais desinteressantes do que os estrangeiros. Historicamente, o público sempre preferiu consumir quadrinhos de super-heróis norte-americanos às produções nacionais, e ainda hoje quadrinhos voltados a temas brasileiros são escassos ou mesmo rejeitados pelo público consumidor. Essa generalização, por sua vez, não pode ser tomada como verdade absoluta, pois segundo CIRNE (1973),

Quando a problemática comunicacional passou a ser estudada e questionada em profundidade, quando a cultura de massa começou a receber um tratamento crítico fundado na semiologia e na Teoria científica da História, os quadrinhos despontaram - ao lado do cinema - revelando uma pujança estética já presente no Little Nemo ${ }^{3}$ de 1905! (CIRNE, 1973, p.9, grifo do autor).

Após a popularização das histórias em quadrinhos por todo o mundo, ocorreu a popularização do mangá, os quadrinhos japoneses. Presentes desde o fim da Segunda Guerra Mundial, de acordo com PEREIRA (2015), foi só a partir dos anos 1990 que o mangá passou a ganhar projeção nacional, impulsionado pela transmissão dos animês - os desenhos animados japoneses - da época.

O século XXI pode ter como característica marcante o boom das adaptações de obras literárias brasileiras para o formato em quadrinhos ${ }^{4}$. $\mathrm{O}$ mercado editorial brasileiro apresentou ao leitor alguns títulos estrangeiros traduzidos e também inaugurou a adaptação de clássicos nacionais para a versão em mangá com a obra Helena ${ }^{5}$.

2 Segundo COVALESKI (2012), "compreende-se que as surgidas posteriormente são (na classificação atual): fotografia, a oitava; quadrinhos, a nona; games, a décima; arte digital, a décima primeira" (2012, p.93, grifos meus).

3 Um dos marcos mais importantes na história dos quadrinhos. Ele foi um personagem criado por Winsor McCay para as tirinhas de domingo dos jornais New York Herald (15/10/1905 a 23/04/1911) e New York American (30/04/1911 a 1913). As mesmas podem ser visualizadas em http://www.comicstriplibrary. org/browse/results?title $=2$.

4 Alguns exemplos podem ser conhecidos no estudo de PINA (2014) em http://www.ufjf.br/ revistaipotesi/files/2016/01/13_Literatura_e_quadrinhos_em_di\%C3\%83\%C2\%A1logo1.pdf.

5 Até o presente momento não houve a tradução desse mangá para outras culturas ou países. 
Por fazer parte do cânone literário, Helena (do folhetim) tende a ser conhecida mais por suas adaptações (em livros) do que pela sua versão original (em folhetim). O mangá seria, assim, uma adaptação diferente e recente dos formatos em livros da novela machadiana, e depende de grandes vendas para seduzir seus leitores "[...] a experienciar a adaptação através das lentes da obra adaptada, como um tipo de palimpsesto" (HUTCHEON, 2013, p.168).

\section{Helena, O Globo e Machado de Assis}

Se não for o maior, Machado de Assis é considerado um dos maiores nomes da Literatura Brasileira de todos os tempos.

Joaquim Maria Machado de Assis (1839-1908) - Nasceu no Morro do
Livramento (Rio de Janeiro). Trabalhou como tipógrafo na Imprensa Nacional,
depois na Tipografia de Paula Brito, entre 1856 e 1858 . A partir dessa data,
até 1867 , foi assíduo colaborador em jornais e revistas cariocas, como
Correio Mercantil, Diário do Rio de Janeiro, Semana Ilustrada, Jornal das
Famílias, onde publicou muitos contos, crônicas e crítica teatral. Ingressou no
funcionalismo público, em 1867. Em 1869, casou-se com Carolina Augusta
Xavier de Novais. Em 1897, foi aclamado presidente perpétuo da Academia
Brasileira de Letras (CAMPEDELLI, S.; JÚNIOR, A, 1991, p.156, grifos do
autor).

Seus livros publicados normalmente são enquadrados em duas fases: primeira ${ }^{6}$ (constituída de Contos Fluminenses [1870], Histórias da Meia-Noite [1873], Ressurreição [1872], A Mão e a Luva [1874], Helena [1876] e Iaiá Garcia [1878]) e segunda7 (Ocidentais [1880], Histórias sem Data [1884], Várias Histórias [1896], Páginas Recolhidas [1889], Relíquias da Casa Velha [1906], Memórias Póstumas de Brás Cubas [1881], Quincas Borba [1891], Dom Casmurro [1889], Esaú e Jacó [1904], Memorial de Aires [1908]), além de sua produção poética (Crisálidas e Falenas [1864]) e dramatúrgica (Desencantos [1861] e Queda que as Mulheres Têm para os Tolos [1861]). Machado de Assis

[...] experimenta duas fases em sua vida literária: a primeira, de inspiração tipicamente romântica. Escreve, para o jornal Marmota, a comédia Queda que as Mulheres têm pelos Tolos. Escreve, logo a seguir, a fantasia dramática intitulada Desencantos. No ano de 1864 publica o primeiro livro de poesias Crisálidas, para seis anos mais tarde publicar Contos Fluminenses. Posteriormente escreve Falenas e Americanas, Histórias da Meia-Noite, Helena, A Mão e a Luva, Iaiá Garcia. A segunda fase revela a plenitude literária do escritor. Produz Memórias Póstumas de Brás Cubas, Quincas Borba, Dom Casmurro, Esaú e Jacó e Memorial de Aires. Ainda escreve os livros de contos Histórias sem Data, Papéis Avulsos e o livro de poesias Ocidentais (QUADROS, 1966, p.128, grifos do autor).

\footnotetext{
6 Também conhecida como "fase romântica".

7 Também conhecida como "fase realista".
}

Metamorfoses, Rio de Janeiro, vol. 15, número 2, p. 72-84, 2019. 
Helena foi publicado originalmente em forma de folhetim no jornal $O$ Globo $^{8}$ de 6 de agosto de 1876 (edição $n^{\circ} 211$ ) a 11 de setembro de 1876 (edição ${ }^{\circ} 245$ ).

Pensando em economia, sem dúvidas, estávamos diante de uma folha de teor liberal. Se pensarmos em popularidade, podemos dizer que, em seus inícios, não havia nenhum tipo de concessão, em termos formais, ao público leitor, porém, com tempo, os preços baixam e a linguagem também se torna cada vez mais acessível. Quanto a uma identificável roupagem moderna, podese afirmar que o discurso progressista sempre fora uma constante entre os editores do jornal desde sua fundação. Isto posto, em suas páginas, nos deparamos com um noticiário ligado especialmente ao mundo do trabalho e da economia, tudo isso contemplado de maneira não restrita somente ao cenário do Rio de Janeiro, pelo contrário, pois, como o título sugere, $O$ Globo tinha a intenção de abarcar o mundo todo. Dito isto, elencamos mais uma característica importante deste jornal: seu teor internacionalista (SALVAIA, 2014 b, p.1-2, grifos do autor).

Além disso, o jornal parecia “deselitizar" a literatura para poder ampliar seu número de consumidores/leitores (SALVAIA, 2014a, p.24). Isso pode ser confirmado devido ao fato de que o romance já se encontrava completo antes mesmo de ser "recortado" em capítulos para estrear em folhetim (SALVAIA, 2014a, p.141).

Machado de Assis, nesse momento, se mostra um escritor mais “[...] sóbrio, ciente de seu papel no campo das letras e conhecedor de diversas formas de expressão literária colhidas nos meios jornalísticos pelos quais transitou", contrário à intempestividade do início da carreira (SALVAIA, 2014a, p.25).

Se enquadrada de forma simplista, a obra pertenceria à fase romântica do autor, contida no ciclo Ressurreição, A mão e a Luva, Iaiá Garcia e Helena. O diferencial da última em relação a suas predecessoras é que

8 "Publicado diariamente, $O$ Globo era sempre constituído por quatro páginas. Na primeira, eram frequentes as notícias sobre chegadas e partidas de paquetes, oscilações cambiais ao redor do mundo e cotações de mercadorias (especialmente agrícolas). Além disso, e também nas páginas iniciais, eram comuns as publicações de artigos teóricos bastante rebuscados que tratavam de liberalismo, intervencionismo estatal, filosofia positivista, entre outros temas. A parte do rodapé era sempre reservada ao folhetim, que em alguns momentos cedia espaço a textos sobre crítica literária, teatral, ou ainda, a diversas anedotas históricas. As segundas e terceiras páginas eram geralmente dedicadas às notícias da Corte e das Províncias, as pautas giravam em torno das atualidades sobre política, economia, além do noticiário recorrente. Nessas páginas também é possível observar uma das principais características do Globo: seu teor internacionalista. As notícias enviadas por correspondentes ou retiradas de jornais estrangeiros (principalmente franceses, ingleses, portugueses e norte-americanos) eram exaustivamente publicadas pela folha. De forma esporádica e, em alguns momentos, em temporadas contínuas, também vinha à tona a coluna Variedades, que ao longo do tempo acrescentaria novos rumos ao jornal. A quarta página sempre era destinada aos anúncios publicitários dos mais variados produtos e dos mais variados ofertantes" (SALVAIA, 2014b, p. 16, grifos do autor). 
[...] tem todos os elementos que correspondiam às expectativas do público burguês da época: era melodramático, com uma trama envolta em segredos e um amor impossível, nesse caso incestuoso, que só poderia encontrar resposta na tragédia. Embora não chegue a ser um romance de costumes, Helena retrata aspectos da família brasileira: a estrutura familiar patriarcal baseada no cultivo de sua dignidade pessoal e de seus valores espirituais, amparados pela igreja Católica (STUDIO SEASONS, 2014, p.5, grifos meus).

Outras características como melancolia, ironia, linguagem culta e exaltação aos traços fortes do feminino também são trabalhadas no enredo. Helena, acrescenta Helen Caldwell, foi uma grande evolução ocorrida desde $A$ mão e a luva, apresentando ao leitor tom mais leve e cômico. (SALVAIA, 2014a, p.26).

O romance Helena é classificado também como "romance urbano", pois critica os costumes sociais do século XIX, tema mais explorado nele. Seu autor, nesse momento, tem a experiência de cronista e crítico de vários jornais e revistas das décadas de 1850 e 1860:

Nos romances da década seguinte, a representação dos temas ligados ao esclarecimento das questões específicas daquela sociedade, estará bem melhor desenvolvido [sic] pelo narrador machadiano. Em Helena (1876), o leitor fica sabendo muitas das informações sobre o mundo dos dependentes, através da personagem Helena e dos comentários do narrador. O tipo de parasitismo social aqui abordado é o do mundo dos agregados, os dependentes da vontade senhorial (GRANJA, 1997, p.260, grifo do autor).

O tempo desse romance gira em torno da década de 1850 , em meio a uma sociedade excessivamente religiosa (católica). A linguagem empregada pelo autor é uma combinação de ironia e melancolia, que funciona como uma crítica à sociedade de aparências. Seu narrador é onisciente e é capaz de fazer uma análise psicológica das personagens. A protagonista - que dá nome ao romance - é, logicamente, a figura mais analisada, assim como seus fins e meios. A trama possui suspense e, no seu decorrer, o leitor tem como "missão" desvendar o segredo que Helena carrega consigo através de pistas que a narrativa (e a própria Helena) lhe concede, das quais “[...] algumas são fornecidas pelos comportamentos estranhos de Helena; no entanto, é o narrador quem as complementa com suas informações e insinuações” (GRANJA, 1997, p.264).

Segundo LIPSZYC (1972), a preferência por uma obra que contém suspense para ser convertida em mangá mostrou-se uma boa escolha, pois "o suspense diz ao leitor o suficiente sobre algum problema interessante logo no começo da história" (LIPSZYC, 1972, p.242, grifos do autor). Helena traz ao leitor algo diferente do convencional crime de "romance policial" acontecido na primeira cena, o qual instiga o leitor a descobrir seu motivo/motivador ao longo do texto, porém o suspense surge paulatinamente, de acordo com comportamentos perturbados que a protagonista passa a apresentar aos personagens e ao leitor. 


\section{Helena x Helena: comparações}

É tarefa importante dos estudos literários comparar ambas as obras, pois se aprecia, assim, “[...] melhor os verdadeiros valores da história das ideias e dos textos" (CLAUDON; HADDADWOTLING, 1992, p.21). As leituras de Helena, de Machado de Assis, assim como de Helena, de Studio Seasons, podem ser mais bem compreendidas caso o leitor tenha conhecimento de ambas as obras e estabeleça intertextos. Isso não significa que, se um leitor tiver seu primeiro contato com a obra pela versão em mangá, nada abstrairá da versão original em folhetim, num contato posterior à versão em quadrinhos do clássico literário. "Nesta circunstância, considerar-se-á o facto de que a versão Y que sucede ao original X tem o seu valor próprio; é um texto literário completo, diferente, novo em relação ao texto que, no entanto, o fez germinar" (CLAUDON; HADDAD-WOTLING, 1992, p.22).

Tarefa tão importante quanto à tradução, "[...] a adaptação é uma forma de transcodificação de um sistema de comunicação para outro" (HUTCHEON, 2013, p.9). Sendo o primeiro estúdio responsável pela adaptação de obras literárias brasileiras para versão em mangá,

O Studio Seasons foi criado em 1996 com o objetivo de produzir e divulgar técnicas de mangá. É formado pelas garotas Monserrat, Sylvia Feer e Simone Beatriz.

O grupo participou da antologia Manga Booken, de 1997, e publicou na Neotokyo as obras Zucker e Mitsar. Também lançaram fanzines como Oiran e Sete dias em Alesh.

Em 2004, através da editora NewPOP, publicaram a compilação de Zucker. A história utiliza a narrativa shojo para contar uma fábula do Rio Grande do Sul, com forte apelo regional e grande qualidade técnica.

O estúdio continua ativo e com muitos projetos em andamento, como a adaptação em mangá do livro Helena, de Machado de Assis [já concluída, publicada e comercializada]! (PEREIRA, 2015, p.106, grifos e comentários meus).

O mangá Helena, de fato, consegue ser experienciado como adaptação devido a sua fidelidade mimética ao original em boa medida; afinal, para que o novo produto funcione dessa forma é necessário manter o máximo da obra original em si “[...] justamente por causa das mudanças entre as mídias e os contextos" (HUTCHEON, 2013, p.223). De acordo com o Studio Seasons, assim se procedeu à adaptação do folhetim para o mangá:

[...] foi um processo que exigiu algumas mudanças. Na primeira fase, reconstruímos as cenas para que pudessem se encaixar na linguagem gráfica do mangá. Como o material tinha um número definido de páginas, a história sofreu cortes, ao mesmo tempo em que tivemos de recriar cenas que eram vitais para dar veracidade ao relacionamento Helena - Estácio assim como outros foram criados para compensar a ausência da narrativa. Mantivemos grande parte dos diálogos originais (as falas foram, algumas vezes simplificadas para o leitor atual) e fomos fiéis a todo o universo visual de 1850, ano em que se passa a história (STUDIO SEASONS, 2014, p.6, grifos meus). 
O grupo Studio Seasons optou por não divulgar muitas informações para manter o sigilo das mesmas, mas possivelmente a preferência por uma obra não tão popular como Helena, se comparada a Memórias Póstumas de Brás Cubas (1881) ou Dom Casmurro (1899), pode ter acontecido porque "quanto mais popular e querido o romance, mais provável o descontentamento" (HUTCHEON, 2013, p.174). Como já supramencionado, Helena foi a primeira adaptação de uma obra canônica nacional para uma versão em mangá e poderia soar muito pretensiosa uma forma de adaptação inédita no Brasil como essa já escolher uma obra tão popular como os dois exemplos acima.

Helena é difícil de ser enquadrado numa classificação rigorosa de mangá, por ser um “mangá made in Brazill'. Sendo uma adaptação de um clássico da literatura nacional, não pode ser certamente destinada a público etário adulto (acadêmico, docente, culto) nem totalmente infanto-juvenil. Classificá-la como literatura simplificada para alunos de Ensino Médio e/ou Fundamental II também seria limitá-la demais. O mesmo enquadramento torna-se complexo para inserir a obra em classificações como público masculino (shonen), feminino (shojo) ou pueril (yonen), pois há no enredo a abordagem psicológica das personagens e suspense permanente. Também não foi possível classificar o mangá analisado em mimético (imitação do original japonês), híbrido (misto de mangá japonês com traços nacionais-originais) ou nacional (se é que se pode afirmar que haja mangá 100\% brasileiro, afirmação ainda hoje discutível).

Esse mangá segue a ideologia de Osamu Tezuka, o qual, segundo Pereira, "[...] defendia que o mangá não devia apenas fazer rir, como nas tiras de 4-koma ${ }^{9}$, mas abraçar todos os sentimentos, inclusive os negativos" (PEREIRA, 2015, p.76, grifos meus). Tal sentimentalismo, representado por lágrimas ${ }^{10}$, aqui é uma recorrente demonstração de sentimento devido a muitas desgraças e desilusões pelas quais os personagens passam, por exemplo.

Além das evidentes diferenças entre linguagem escrita e linguagem visual/escrita, outros aspectos podem ser comparados entre o folhetim e o mangá. Helena começa como geralmente os jornais da época (não necessariamente $O$ Globo) começavam: uma imagem de algum ornamento.

A linguagem da adaptação é culta sem ser arcaica. Podem ser presenciadas na leitura

9 Mangá no formato de tirinhas ou vinhetas de tamanhos iguais. Sua sequência segue o padrão de leitura japonês: de cima para baixo e da direita para a esquerda. Também é conhecido como Yonkoma - mangá de quatro quadros. Informações mais detalhadas e exemplos visuais em http:// naoeminhaculpaquenaosoupopular.blogspot.com.br/2014/12/o-que-e-4-koma.html.

10 Foram encontradas imagens que remetem ao choro, seja com os olhos no início do lacrimejamento, as lágrimas já formadas e correntes ou insinuações de extrema tristeza nas páginas 73, 135, 151, 173, 174, 177, 178, 179 (por duas personagens diferentes), 182, 185, 186 (por duas personagens diferentes), 188, 190, 194, 209, 215 (por duas personagens diferentes), 216, 217, 218, 219, 220 (por duas personagens diferentes), 221, 223, 224, 225 (a personagem está de bruços com a cabeça no travesseiro remoendo suas tristezas), 235, 236, 237 (por duas personagens diferentes), 244, 245 (por três personagens diferentes), 246,247 e 248. 
transcrições completas do original e atualizações em certos vocábulos ou mesmo frases inteiras. Isso evita uma linguagem incompreensível, pedante e tediosa ao jovem leitor, pois

O diálogo é o que dizem os personagens numa história em quadrinhos, mas devem dizê-lo com naturalidade para que pensemos que realmente o dizem, e não devemos deixá-los com os rostos imutáveis quando falam. A expressão é necessária. Aliás, os personagens não devem ser excessivamente loquazes (LIPSZYC, 1972, p.259).

Abaixo seguem dois exemplos comparativos da reprodução fiel ao original e uma releitura, respectivamente:

Exemplo 1:

“- Nhanhã Helena disse que já vem”. (Edição 213, n.1, p.1, Folhetim do Globo)

Fonte: (O GLOBO, n. 213, 09 de agosto de 1876. Transcrição do folhetim Helena, de Machado de Assis).

Exemplo 2:

“- [...] Peço desculpas da demora; estavam à minha espera, creio eu.

- [...] Sentemo-nos, que o almôço esfria". (Edição 213, n.1, p.1, Folhetim do Globo)

Fonte: (O GLOBO, n. 213, 09 de agosto de 1876. Transcrição do folhetim Helena, de Machado de Assis).

Adaptação fiel à obra, Helena demonstra possuir o "argumento" criado por Lipszyc: "um argumento para a história em quadrinhos contém pelo menos um problema a resolver, algum obstáculo à solução do problema, uma crise na tensão dramática e um apogeu, ou, seguindo o apogeu, um desenlace ou explicação" (LIPSZYC, 1972, p.238, grifos do autor). Usufruindo da análise de Lipszyc, o argumento de Helena é constituído por: problema (o amor de Estácio por Helena), obstáculo (o parentesco que faz a possível união ser considerada incestuosa e proibida), crise (a chegada e aproximação de Mendonça, a qual causa ciúmes em Estácio), apogeu (o reconhecimento aceito por Mendonça de não ser digno o bastante para a mão de Helena, manipulado por Estácio), desenlace (a morte de Helena, que encerra as perturbações amorosas de Estácio).

A figura do narrador se mostra neutra no romance de folhetim e praticamente inexiste no mangá, que preza o diálogo e as ações das personagens.

O retrato da época e dos costumes tem a vantagem de ser conhecido visualmente no mangá, conhecimento o qual o leitor só poderia ter com a consulta aos folhetins.

O suspense é mantido durante a narrativa graças à técnica do quebra-cabeça, cujas peças são fornecidas de forma sutil tanto pela protagonista como pelos outros personagens e pelo próprio enredo, que faz com que o leitor entenda aos poucos o que se passa na narrativa. Segundo Lipszyc 
Nunca bastará dizer ao leitor que tal personagem é isto ou aquilo; a palavra, o gesto e a expressão, a ação e o pensamento do personagem devem indicar seu caráter e mentalidade. O leitor não se contenta com a informação do argumentista. O leitor de histórias em quadrinhos quer ver e ouvir, e chegar por si mesmo a conclusões próprias (LIPSZYC, 1972, p.258).

Algumas partes desse quebra-cabeça podem ser o interesse de Helena por cavalgar, sua excessiva timidez, a misteriosa casa (da bandeira azul), dentre outras encontradas pelo leitor ao longo de seu contato textual ${ }^{11}$.

Nesse mangá também se pode perceber (explicitamente) a técnica dos "fantochestitereteiros". Os principais personagens, conforme já mencionado, manipulam e são manipulados constantemente. Isso porque

Os personagens dos Mangás possuem um lado psicológico muito forte. Seus defeitos são atenuados e independente de seu modo de agir, ou do tipo de história, podem rir, chorar e externar os mais diversos sentimentos. Os personagens nascem, crescem, casam-se e morrem (BRAGA JR, 2011, p.95, grifos meus).

Seria prejudicial ao texto a inserção de pequenos fluxos de consciência, julgamentos e tomadas de decisões, pois o deixaria distante da arte narrativa que Machado de Assis exercia em sua "fase romântica". Para uma maior proximidade ao real, é essencial que as personagens possuam personalidades variadas e bem definidas "para que o leitor possa crer na realidade dos personagens de uma história de aventuras, para que lhe deem a impressão de seres humanos [...]" (LIPSZYC, 1972, p.254-255), com exceção de manter os traços físicos das personagens do modelo padrão oriental dos quadrinhos modernos.

Não há descrição dos locais no folhetim, apenas menções. O recurso visual é característica fundamental nos quadrinhos e podem sugerir imagens ao leitor ${ }^{12}$, com o intuito de suprir a falta de detalhamento. Andaraí e Rio Comprido, locais do Rio de Janeiro onde se passa a história, são apenas dois exemplos.

$\mathrm{Na}$ adaptação o suspense inicial sobre o testamento do Conselheiro Vale foi retirado. $\mathrm{O}$ conteúdo do capítulo I do folhetim é voltado inteiramente para isso, mas logo nas páginas iniciais do mangá já se sabe o conteúdo do documento do conselheiro. Possivelmente a supressão de enredo se deu por conta de economia de espaço, tendo em vista que os mangás possuem em média 100 (quando publicados em "formatinho" ${ }^{13}$ ) ou 200 páginas ${ }^{14}$ (quando em brochura).

11 Pode-se dizer que partes que envolvem algum mistério no ar podem ser encontradas nas páginas 46, 47, 50, 51, 56, 57, 68, 69, 79, 80, 81, 83, 84, 85, 90, 104, 107, 108, 115, 163, 164, 172, 173, 174, 178 e 179. 12 Imagens das residências e panorama geral da vizinhança podem ser vistas nas páginas 10, 13, 16, $17,31,38,39,42,46,47,69,80,115,123,132,145,154,155,163,241,242,244$ e 253.

13 Formato de revistas muito usado em histórias em quadrinhos infanto-juvenis no Brasil. Revistas da Disney e Turma da Mônica são alguns exemplos do mesmo. Também pode ser conhecido como "formato pato" e assemelha-se às dimensões de uma folha de papel A5 $(13 \mathrm{~cm}$ x $21 \mathrm{~cm})$. Mais informações em https://pt.wikipedia.org/wiki/Formatinho.

14 O mangá Helena possui, por sua vez, 256 páginas em formato de brochura. 
Há a descrição das personagens no folhetim. No mangá, por sua vez, o leitor passa a conhecê-las intuitivamente e paulatinamente, através de expressões, falas e atitudes das mesmas ao longo da narrativa, levando em consideração, obviamente, que o traço do mangá é algo muito distante das proporções físicas "reais" das personagens.

O desenho do comic americano tende a seguir os parâmetros da proporção grega do corpo humano e as regras da perspectiva desenvolvidas no renascimento. $\mathrm{O}$ estilo nipônico, presente nos mangás, subverte algumas destas regras de proporção, onde os contornos das massas cranianas e faciais, a pormenorização dos traços fisionômicos como olhos, pálpebras e boca são simplificados e assumem uma volatilidade incomum no mundo do desenho (BRAGA JR, 2011, p.74, grifos meus).

Quando as personagens são inseridas em determinadas situações, o leitor se depara com suas mudanças de comportamento. Tal interpretação é facilitada pela artifício do mangá em ressaltar suas expressões:

Ilustrações de modas são fartamente trabalhados no mangá. Por ser uma obra pertencente e ambientada no século XIX, a escolha do estilo mangá muito agregou quando se optou por trabalhar com a moda vigente, pois

Existe [...] uma grande preocupação com a cabeça dos personagens e suas vestes, que sempre são bem trabalhadas, nos mínimos detalhes. Já outros elementos como estrutura do corpo, detalhes dos membros, compleição física e proporções reais são deixados de lado. Cenários são muitas vezes dispensados. Os personagens são desenhados em fundos brancos ou acompanhados de linhas de ação (BRAGA JR, 2011, p.75).

As onomatopeias são amplamente trabalhadas no decorrer da narrativa ${ }^{15}$, pois "nos mangás, ao contrario [sic] dos quadrinhos ocidentais, as onomatopeias são completamente integradas ao desenho" (BRAGA JR, 2011, p.87, grifos meus).

Quanto à divisão dos capítulos, o mangá é dividido em cinco partes, mas uma melhor e mais próxima divisão dos 28 capítulos do folhetim original pode ser compreendida na seguinte estrutura:

Quanto a essa nova divisão de capítulos, poucas complicações da conversão folhetimmangá são presenciadas. Um exemplo é uma cena contida no capítulo VII do mangá que faria parte do capítulo VI no folhetim, no qual Helena está com os livros Paulo e Virginia e Manon Lescaut.

15 No mangá Helena aparecem onomatopeias nas páginas 46, 48, 49 (duas diferentes entre si), 51 (três iguais em diferentes quadrinhos), 55 (duas diferentes entre si), 60, 69, 71, 81 (duas diferentes entre si e duas iguais em diferentes quadrinhos), 84, 87, 95, 99, 109 (duas diferentes entre si), 112, 114, 119, 126, 128, 129, 130 (duas diferentes entre si), 133 (duas diferentes entre si), 154, 164, 165 (duas diferentes entre si), 167, 179, 180, 184, 189, 191, 192, 200 (duas diferentes entre si), 226, 231 (duas diferentes entre si), 238, 239, 240 (duas diferentes entre si), 251, 254. 
A simbologia empregada no enredo não segue a tradição das imagens metafóricas japonesa, como por exemplo a presença de flores como a cerejeira e o crisântemo ${ }^{16}$. Buscando maior proximidade em relação ao Brasil, o enredo empregou flores que fazem parte da flora brasileira, como a peônia ${ }^{17}$ e a gérbera ${ }^{18}$, simbolizando a beleza e a longevidade, respectivamente. Pelo mesmo motivo as folhas de ginkgo ${ }^{19}$ e de bordo $^{20}$ ficaram de fora (embora o lírio ${ }^{21}$ tenha aparecido por uma vez só na estória). Um leitor atento percebe o simbolismo das flores nacionais e folhas simples ${ }^{22}$ que aparecem ao longo da narrativa ${ }^{23}$, as quais podem representar o ciclo da vida: enquanto estão na árvore ainda são "jovens"; ao vento estão no "curso da vida"; e, caídas, no fim de seu ciclo.

Tendo em vista as informações supracitadas,

Podemos dizer que a produção de mangá é muito afetada pelo meio.

Ela reflete uma sociedade que se expressa e se identifica há décadas pelas HQs em todas as esferas sociais. E como a sociedade, está em constante movimento, atualização e reciclagem (PEREIRA, 2015, p.80, grifos meus).

Já as cenas que transmitem a sensação de felicidade são representadas por animais pacíficos, providos de grande beleza estética, como passarinhos e borboletas.

A tradição cinematográfica também exerce papel importante no mangá em questão, assim como muitos outros. Técnicas como o super-close e movimentos diversos estão presentes no mangá Helena. Nos movimentos, por exemplo, aparecem traços que os indicam, técnica imortalizada por Osamu Tezuka.

16 A cerejeira e o crisântemo, também conhecidas como sakura e kiku, são importantes símbolos na cultura japonesa. Informações completas em http://mundo-nipo.com/cultura-japonesa/ costumes/26/12/2015/significado-das-flores-no-japao/.

17 Mais informações sobre a simbologia das flores na cultura japonesa em http://mundo-nipo.com/ cultura-japonesa/mitos-e-lendas/10/02/2014/princesa-aya-e-o-espirito-da-peonia/.

18 Flor que simboliza a simplicidade, alegria, nobreza, sensibilidade, amor ou sensualidade. Informações adicionais em http://www.mulhervirtual.com.br/flor/Gerbera.html.

19 Ela tornou-se símbolo de paz e longevidade por ter sobrevivido às explosões das bombas atômicas durante a Segunda Guerra Mundial. Outras informações em https://vidasemvoltas.blogspot.com. br/2014/11/ginkgo-as-folhas-amarelas-do-outono-no.html.

20 Folhas da planta de mesmo nome, também conhecida no Japão como momiji. Suas folhas ficam avermelhadas e caem no outono. Mais informações em https://arvoresvivas.wordpress.com/2007/11/29/ momiji-direto-do-japao/.

21 Uma curiosidade é que metade das espécies dos lírios do mundo localizam-se no Japão e na China, mesmo sendo popular em diversas partes do mundo e nem tanto no Japão. Outras informações em http:// iloveflores.com/flor-de-lirios-especies-cores-usos-significados-origem/.

22 Aqui, entende-se por folha simples a folha que possui limbo único, contínuo, sem divisão de lâminas menores. Imagens e explicações breves para seus diferentes tipos em https://morfoanatomiavegetal. wordpress.com/folha/morfologia/.

23 Folhas desse tipo aparecem nas páginas 35, 50, 51, 53, 54, 55, 76, 107, 113, 191, 210, 212, 229, $231,232,233,236$ e 256 . 
Um recurso do animê $\hat{~}^{24}$ empregado é o aproveitamento de imagens, que facilita na produção do mangá devido à economia de trabalho aos mangakás, por lhes permitirem usar uma mesma imagem e/ou alterá-la levemente para compor outro quadrinho, dispensando todo o trabalho de uma nova criação. Como as ações e personagens são mais importantes do que o cenário de fundo, essa técnica funciona bem no mangá.

Uma certa poeticidade pode ser, por vezes, encontrada na relação texto-imagem. Um exemplo é a evolução do que Salvador narra paralelamente ao ciclo de vida das peônias, que representam a alegria do pai de Helena ("desabrochada") com o convívio com a filha, mas que adoece de acordo com os acontecimentos seguintes em sua vida:

E muitos outros exemplos podem ser extraídos do mangá, em comparação ao romance de folhetim.

\section{Considerações finais}

A literatura, o mangá, o leitor e os estudos acadêmicos só terão a ganhar com a adaptação em estudo para efeitos comparatistas e semióticos, podendo inspirar novas versões de clássicos a fim de incentivar a leitura jovem e o interesse à nona arte, dentre outros benefícios.

Mesmo o Brasil ter apenas iniciado esse processo de adaptação de seus clássicos literários para a versão mangá, o caso de Helena é um ótimo exemplo do quanto uma obra pode aludir à outra e completá-la/atualizá-la, tendo em vista outros públicos e seus respectivos tempos, oferecendo a ambos os leitores (do folhetim e do mangá) o conhecimento da época e do enredo da obra-fonte e de sua nova versão. Com isso, o interesse da leitura pode se mostrar uma via de mão dupla que leva o leitor do folhetim ao mangá e vice-versa.

\section{REFERÊNCIAS}

BRAGA JR, A. X. Desvendando o Mangá Nacional: Reprodução e Hibridização nas Histórias em Quadrinhos. Maceió: EdUFAL, 2011.

CAMPEDELLI, S.; JÚNIOR, A. Tempos da Literatura Brasileira. 10. ed. São Paulo: Círculo do livro, 1991.

CIRNE, M.

. A linguagem dos quadrinhos. O universo estrutural de Ziraldo e Maurício de Sousa. 3. ed. Petrópolis: Vozes, 1973.

CLAUDON, F.; HADDAD-WOTLING, K. Elementos de Literatura Comparada: teorias e métodos da abordagem comparatista. Lisboa: Inquérito, 1992.

COVALESKI, R. L. Artes e comunicação: a construção de imagens e imaginários híbridos.

24 Desenho animado japonês.

Metamorfoses, Rio de Janeiro, vol. 15, número 2, p. 72-84, 2019. 
Galaxia Revista do Programa de Pós-Graduação em Comunicação e Semiótica. São Paulo, n 24, p. 89-101, dez. 2012.

GRANJA, L. À Roda dos Jornais (e teatros): Machado de Assis, Escritor em Formação. 1997. 325f. Tese (Doutorado em Teoria Literária) - Universidade Estadual de Campinas, Campinas, 1997.

HUTCHEON, L. Uma teoria da adaptação. Trad. André Cechinel. 2 ed. Florianópolis: Editora da UFSC, 2013.

LIPSZYC, E. História em quadrinhos e seu argumento. In: . (Org.) Shazam!. Coleção

Debates. São Paulo: Perspectiva, 1972. p. 237-260

PEREIRA, A. C. Além dos olhos grandes: um estudo em mangá sobre mangá. Curitiba: Edição do autor, 2015.

PINA, P. K. C. Literatura e quadrinhos em diálogo: Adaptação e leitura hoje. Ipotesi. Juiz de Fora, v.18, n 2, p. 149-164, jul./dez. 2014.

QUAdros, J. Curso Prático da Língua Portuguesa e Sua Literatura. $1^{\circ}$ ed. São Paulo: Formar, 1966. 5 v., II.

SALVAIA, P. Diálogos possíveis: o folhetim Helena (1876), de Machado de Assis, no jornal O Globo. 2014. 166f. Dissertação. (Mestrado em Teoria e História Literária). Universidade Estadual de Campinas, Campinas. 2014a.

. O folhetim em meio ao jornal: algumas observações sobre as possibilidades de recepção do romance Helena (1876), de Machado de Assis, através das páginas do Globo. VII Simpósio Nacional de História Cultural História cultural: escritas, circulação, leituras e recepções. Nov/2014b, p. 1-13.

STUDIO SEASONS. Helena. Adaptação da obra de Machado de Assis. São Paulo: NewPOP, 2014. 